\title{
Severe atypical herpes zoster as an initial symptom of fatal myelodysplastic syndrome with refractory anemia and blast excess (RAEB II)
}

This article was published in the following Dove Press journal:

Clinical, Cosmetic and Investigational Dermatology

18 May 2017

Number of times this article has been viewed

\author{
Uwe Wollina' \\ Gesina Hansel' \\ Anja Baunacke' \\ Georgi Tchernev² \\ 'Department of Dermatology and \\ Allergology, Academic Teaching \\ Hospital Dresden-Friedrichstadt, \\ Dresden, Germany; ${ }^{2}$ Department \\ of Dermatology and Dermatologic \\ Surgery, Medical Institute of Ministry \\ of Interior (MVR), Sofia, Bulgaria
}

Correspondence: Uwe Wollina Department of Dermatology and Allergology, Academic Teaching Hospital Dresden-Friedrichstadt, Friedrichstrasse 4I, 01067 Dresden, Germany

Email wollina-uw@khdf.de

\begin{abstract}
Herpes zoster is a common disease caused due to varicella zoster virus (VZV) infection with increasing incidence by age. If the patient has a severe, extended, or treatmentrecalcitrant course of herpes zoster, this must be a red flag to search for underlying pathologies. Here, we report about a 64-year-old male patient with diabetes, who came to our emergency department because of general malaise, fever, chills, and a pronounced nuchal and facial swelling on the left side. Based on herpetiform-grouped vesicles and yellowish crusts, an impetiginized facial herpes zoster was diagnosed, and combined antiviral and antibiotic treatment was initiated. He was HIV negative. Despite intensified treatment, his situation worsened. We observed blasts in peripheral blood, but bone marrow biopsy was initially denied. Some days later after deterioration of his disease, he accepted further diagnostics. A myelodysplastic syndrome with blast excess (refractory anemia and blast excess II, RAEB II) could be confirmed. The following translocations were detected: $\mathrm{t}(2 ; 12)(\mathrm{p} 13 ; \mathrm{q} 13)$ and $\mathrm{t}(6 ; 9)(\mathrm{p} 22 ; \mathrm{q} 34)$. REAB II has an unfortunate prognosis. Cytoreductive treatment was initiated by the hemato-oncologist. Unfortunately, the patient deceased due to septic shock.
\end{abstract}

Keywords: herpes zoster, varicella zoster virus, myelodysplastic syndrome, sepsis, emergency

\section{Introduction}

Herpes zoster is caused by varicella zoster virus (VZV). After a short prodromal stage, a dermatomal eruption of herpetiform-grouped vesicles develops due to reactivation of VZV within ganglia and their anterograde transport into axons innervating the skin. Common symptoms are pain, dysesthesia, and paresthesia. ${ }^{1}$

Severe zoster subtypes are characterized by ulcerations, necrosis, or dissemination, with or without vasculitis, paresis, central nervous system involvement, or involvement of other internal organs. ${ }^{1}$ Facial edema is another possible symptom ${ }^{2}$ (Table 1). Severe zoster infections are a red flag for serious underlying disorders such as infections, immunodeficiency, and malignancies.

\section{Case report}

A 64-year-old male was admitted to our department as an emergency. He suffered from general malaise, fever, chills, and a pronounced nuchal and facial swelling on the left side. Since birth, he suffered from left-sided microtia with complete absence of meatus acusticus. His medical history was positive for diabetes mellitus type 2 treated by diet and an arterial hypertension controlled by $160 \mathrm{mg}$ valsartan $160 \mathrm{mg} / \mathrm{d}$. 
Table I Differential diagnosis of facial swelling

\begin{tabular}{|c|c|}
\hline Disorders & Remarks \\
\hline Acute hemorrhagic edema & $\begin{array}{l}\text { Children, after infections, vaccination or } \\
\text { drug-induced }\end{array}$ \\
\hline Allergic contact dermatitis & Due to aeroallergen or hair dyes \\
\hline Angioedema & $\begin{array}{l}\text { Acquired type (mast cell-related or } \\
\text { bradykinin-induced); hereditary type with } \\
\text { absolute or functional deficiency of } \mathrm{Cl} \\
\text { esterase inhibitor }\end{array}$ \\
\hline $\begin{array}{l}\text { Brachiocephalic venous } \\
\text { compression, vena cava } \\
\text { superior syndrome }\end{array}$ & $\begin{array}{l}\text { Due to multinodal gout, after venous } \\
\text { puncture, and due to tumors }\end{array}$ \\
\hline $\begin{array}{l}\text { Cushing syndrome, } \\
\text { Mb. Cushing }\end{array}$ & $\begin{array}{l}\text { Steroid-induced (syndrome) ACTH } \\
\text { overproduction, buffalo hump }\end{array}$ \\
\hline Drug induced & $\begin{array}{l}\text { Eg by folic acid antagonist pemetrexed or } \\
\text { dipeptidyl peptidase } 4 \text { inhibitor vildagliptin, } \\
\text { periorbital }\end{array}$ \\
\hline Erysipelas & Fever, erythema, hyperthermia \\
\hline Lepra & Facies leontina \\
\hline Lymphedema & $\begin{array}{l}\text { Secondary after surgery and/or irradiation } \\
\text { of head-and-neck cancer }\end{array}$ \\
\hline Mb. Morbihan & $\begin{array}{l}\text { Solid facial erythema with rosacea } \\
\text { (Glabella, cheeks, lids) }\end{array}$ \\
\hline Strangulation & Strangulation marks \\
\hline Subcutaneous emphysema & After trauma, skin crackling \\
\hline Lymphomas & Fever, hepato-splenomegaly, fatigue \\
\hline Posttraumatic/postsurgery & Medical history \\
\hline Zygomycosis & $\begin{array}{l}\text { Rhino-cerebral type, hyposmia, nasal } \\
\text { secretions }\end{array}$ \\
\hline
\end{tabular}

Abbreviation: ACTH, adrenocorticotropic hormone.

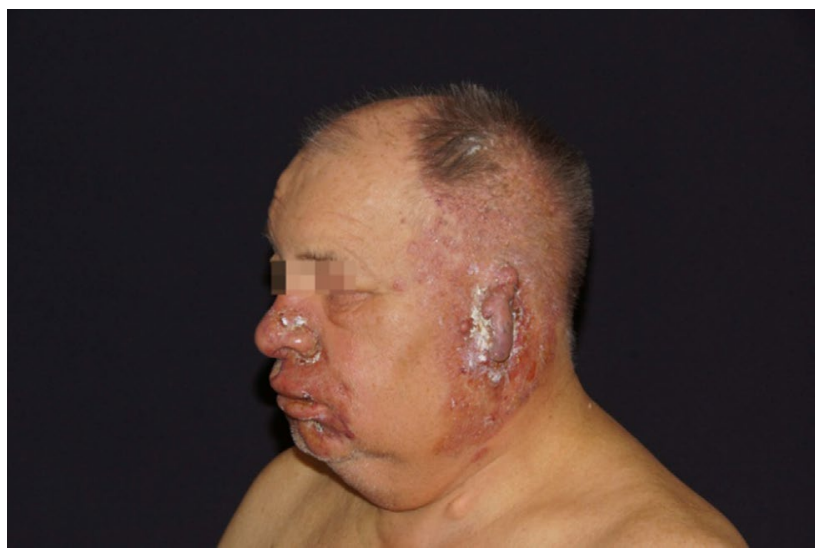

Figure I Initial presentation of the patient with temporal herpes zoster.

On examination, we observed a left-sided head-and-neck edema with herpetiform-grouped vesicles around the left ear and on the nose and yellowish crusts and formation of bullae in the perioral region (Figures 1 and 2). Laboratory findings were remarkable for leukocytosis with a white blood cell count of 25.7 (normal range: 3.8-11.0), thrombocytopenia of $64 \mathrm{Gpt} / \mathrm{L}$ (120-340), lowered hematocrit of $0.245 \mathrm{~L} / \mathrm{L}(0.40-0.54)$, hemoglobin of $5.1 \mathrm{mmol} / \mathrm{L}(8.6-$ 12.1), erythrocyte count of $2.5 \mathrm{Tpt} / \mathrm{L}$ (4.6-6.2), neutrophilia

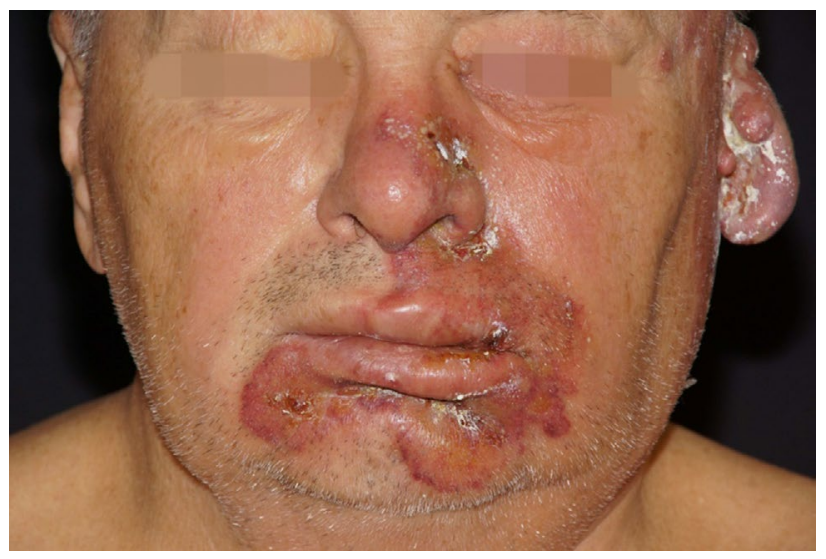

Figure 2 Perioral bullous impetigo, herpetiform vesicles on the nose.

of $13.8 \mathrm{Gpt} / \mathrm{L}(1.8-7.6)$, lymphopenia of $11 \%(20-45)$, increased number of large unstained cells with $2 \mathrm{Gpt} / \mathrm{L}$ $(0-0.40)$, and C-reactive protein (CRP) of $333 \mathrm{mg} / \mathrm{L}(<5)$. HIV tests were negative.

Before submission, antibiotic treatment with sultamicillin was started and continued after submission at a dosage of $3 \times 3 \mathrm{~g} / \mathrm{d}$ intravenously (iv). The facial swelling, however, worsened. Therefore, the patient was referred to our Ear Nose Throat-department for diagnostics. Diagnostic ultrasound and thoracic computerized tomography $(\mathrm{CT})$ were performed to exclude a bacterial or mycotic abscess formation.

With the diagnosis of impetiginized herpes zoster, antibiotic treatment was changed to $3 \times 800 \mathrm{mg}$ clindamycin/d plus aciclovir $3 \times 500 \mathrm{mg} / \mathrm{d}$. Pain management was realized using metamizole sodium $3 \times 30 \mathrm{gtt} / \mathrm{d}$. During the following days, only a minor clinical improvement was seen. In the peripheral blood, $11 \%$ blasts were noted. A bone marrow biopsy was suggested, but the patient refused.

The further course was characterized by malodorous oozing, formation of bullae, and increasing edema. On the left chin and left submandibular region, firm infiltrates were noted, and skin biopsies were taken to exclude specific infiltrates of a malignancy. Histopathology, however, was nonspecific, demonstrating only a putrid inflammation. Vesicles showed dissemination suggesting zoster generalisatus (Figures 3 and 4). Accordingly, we increased the dosage of aciclovir to $10 \mathrm{mg} / \mathrm{kg}(3 \times 1000 \mathrm{mg} / \mathrm{d})$ iv. The pain sensations become worse, and pregabalin was started in increasing doses. Certoparin sodium 3000 I.E. anti-Xa/d was injected subcutaneously for thrombosis prophylaxis.

Nevertheless, the situation did not improve. CRP increased to $>400 \mathrm{mg} / \mathrm{L}$, leukocytosis of $28.4 \mathrm{Gpt} / \mathrm{L}$ developed, and procalcitonin increased to $3.65 \mathrm{ng} / \mathrm{mL}$ (normal range: $0-0.5$ ). 


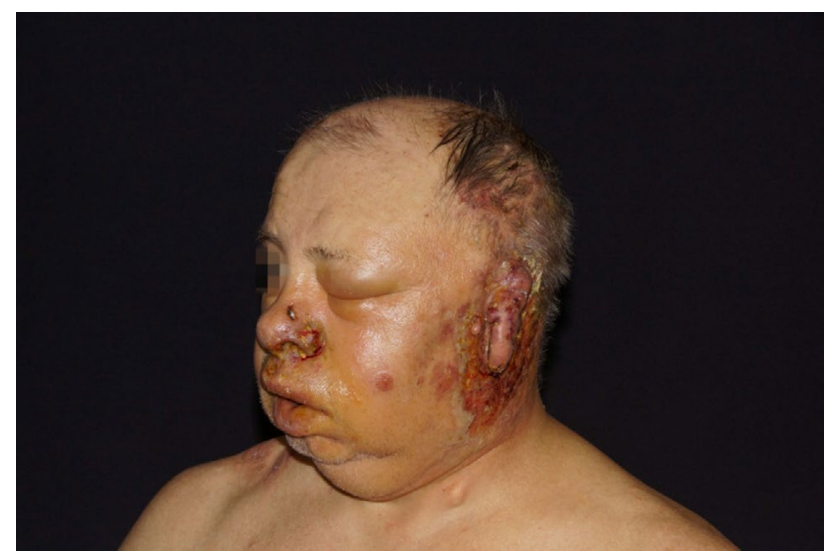

Figure 3 Increased facial edema and necrotic herpes zoster lesions.

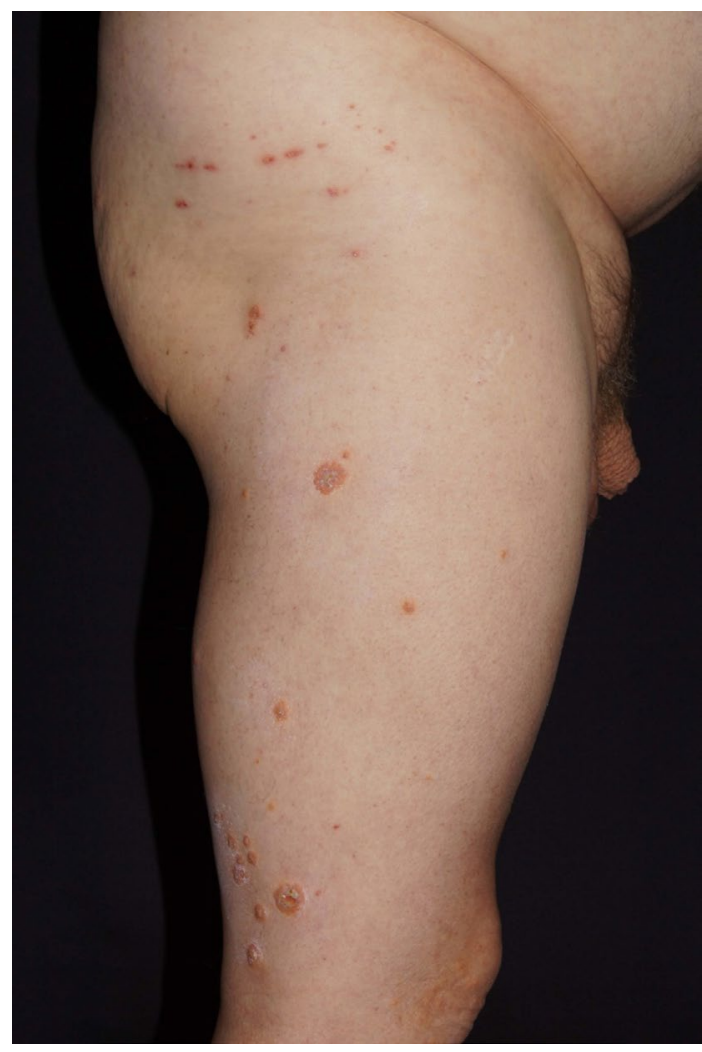

Figure 4 Generalization of herpes zoster vesicles.

Under the suspicion of septicemia, we transferred the patient to the intensive care unit. Central venous access was realized by a subclavian catheter. The patient was treated by $4.5 \mathrm{~g}$ piperacillin, $500 \mathrm{mg}$ levofloxacin, $1000 \mathrm{mg}$ acyclovir every 8 hours, and initially $100 \mathrm{mg}$ prednisolone. During the treatment course, he developed doughy stool; therefore, the antibiosis was changed to vancomycin $4 \times 500 \mathrm{mg}$ per os. Stool samples for Clostridium difficile remained negative. Clinical improvement was accompanied by reduction of vesiculation and edema.
After patient consent, CT and bone marrow biopsy were performed. Bone marrow analysis disclosed atypical myelopoiesis, reduced atypical erythropoiesis, and micromegakaryocytic megakaryopoiesis with $10 \%$ of bone marrow blasts confirming a myelodysplastic syndrome (MDS) refractory anemia and blast excess II (RAEB II). Chromosomal analysis and cytodiagnostics revealed a karyotype 46/XY and translocations t $(2 ; 12)(\mathrm{p} 13 ; \mathrm{q} 13)$ and $\mathrm{t}(6 ; 9)(\mathrm{p} 22 ; \mathrm{q} 34)$. Due to anemia, erythrocyte concentrates were required.

Two weeks after admission, the patient suffered from pain in his right arm. The skin surrounding the subclavian catheter became erythematous. Therefore, the catheter was removed, but microbial cultures of the tip remained negative. Venous duplex sonography disclosed vena subclavia thrombosis and soft tissue hematoma.

In the following days, oozing of the scalp and the ear helix was observed. Microbial swaps identified Pseudomonas aeruginosa.

We intensified diuresis because of a progressive edema. Hemato-oncologist initiated cytoreductive treatment with azacitidine. Anemia and thrombocytopenia required erythrocyte and thrombocyte concentrates. Herpes zoster persisted. During intravenous infusion of varicella immunoglobulin, the patient developed an anaphylactic shock, which could be managed by intensive care. Six days later, the patient died due to a septic shock.

Written informed consent has been obtained from the patient before his tragic outcome to have the case details and any accompanying images published.

\section{Discussion}

In most cases, the diagnosis of herpes zoster can be confirmed clinically by the presence of herpetiform-grouped vesicles and unilateral localization within a dermatome, in combination with pain and paresthesia. ${ }^{3}$ In the present case, a severe zoster with delayed and minimal response to treatment was the red flag for a serious underlying disorder in a patient previously healthy and capable. Antiviral drug therapy was modified accordingly during the course. ${ }^{4}$

Further diagnostics were initially delayed due to patient refusal for bone marrow biopsy. But afterward, the diagnosis of MDS was confirmed.

MDS is accompanied by an increased risk of zoster infection. A recent study using data of Surveillance, Epidemiology and End Result (SEER)-Medicare data base calculated an odds ratio of $1.31 .^{5}$ 
MDS with RAEB is characterized by an increased mortality. RAEB I is defined as a peripheral blast excess $<5 \%$ and bone marrow blasts $<10 \%$, without Auer rods. RAEB II shows peripheral blasts $>5 \%$ and bone marrow blasts $>10 \%$, and Auer rods may occur. ${ }^{6}$ Mean survival of patients with MDS REAB-II is $\sim 16$ months. ${ }^{7,8}$ Translocation $t(6 ; 9)$ (p22;q34) worsens the prognosis with a mean survival of 12 months. $^{9}$

Severe atypical zoster is a red flag. Patients need a workup for serious underlying diseases. Unfortunately, improvement of individual prognosis is not always possible.

\section{Disclosure}

The authors report no conflicts of interest in this work.

\section{References}

1. Wollina U, Machetanz J. Herpes zoster und postzosterische Neuralgie. Hautarzt. 2016;67(8):653-665.

2. Hornstein OP. Differentialdiagnose der Gesichtsschwellungen. HNO. 1979;27(4):129-137.
3. Werner RN, Nikkels AF, Marinović B, et al. European consensus-based (S2k) Guideline on the Management of Herpes Zoster - guided by the European Dermatology Forum (EDF) in cooperation with the European Academy of Dermatology and Venereology (EADV), Part 1: diagnosis. J Eur Acad Dermatol Venereol. 2017;31(1):9-19.

4. Werner RN, Nikkels AF, Marinović B, et al. European consensus-based (S2k) Guideline on the Management of Herpes Zoster - guided by the European Dermatology Forum (EDF) in cooperation with the European Academy of Dermatology and Venereology (EADV), Part 2: treatment. $J$ Eur Acad Dermatol Venereol. 2017;31(1):20-29.

5. Titmarsh GJ, McMullin MF, McShane CM, Clarke M, Engels EA, Anderson LA. Community-acquired infections and their association with myeloid malignancies. Cancer Epidemiol. 2014;38(1):56-61.

6. Bennett JM. Changes in the updated 2016: WHO classification of the myelodysplastic syndromes and related myeloid neoplasms. Clin Lymphoma Myeloma Leuk. 2016;16(11):607-609.

7. DiNardo CD, Garcia-Manero G, Pierce S, et al. Interactions and relevance of blast percentage and treatment strategy among younger and older patients with acute myeloid leukemia (AML) and myelodysplastic syndrome. Am J Hematol. 2016;91(2):227-232.

8. Breccia M, Latagliata R, Cannella L, et al. Analysis of prognostic factors in patients with refractory anemia with excess of blasts (RAEB) reclassified according to WHO proposal. Leuk Res. 2009;33(3):391-394.

9. Gupta M, Ashok Kumar J, Sitaram U, et al. The t(6;9)(p22;q34) in myeloid neoplasms: a retrospective study of 16 cases. Cancer Genet Cytogenet. 2010;203(2):297-302.
Clinical, Cosmetic and Investigational Dermatology

\section{Publish your work in this journal}

Clinical, Cosmetic and Investigational Dermatology is an international, peer-reviewed, open access, online journal that focuses on the latest clinical and experimental research in all aspects of skin disease and cosmetic interventions. This journal is included on PubMed. The manuscript management system is completely online and includes a very quick and fair peer-review system, which is all easy to use. Visit http://www.dovepress.com/testimonials.php to read real quotes from published authors

\section{Dovepress}

